(c) American Dairy Science Association, 2006.

\title{
A Survey of Foodborne Pathogens in Bulk Tank Milk and Raw Milk Consumption Among Farm Families in Pennsylvania
}

\author{
B. M. Jayarao, ${ }^{\star 1}$ S. C. Donaldson,, B. A. Straley, ${ }^{\star}$ A. A. Sawant, ${ }^{*}$ N. V. Hegde, ${ }^{\star}$ and J. L. Brown† \\ *The Department of Veterinary Science, and \\ †The Department of Food Science, The Pennsylvania State University, University Park 16802
}

\begin{abstract}
A 2-part study was conducted to determine the risk of exposure to human pathogens from raw milk. The first part of the study focused on determining raw milk consumption habits of dairy producers. A total of 248 dairy producers from 16 counties in Pennsylvania were surveyed. Overall, 105 (42.3\%) of the 248 dairy producers consumed raw milk and 170 (68.5\%) of the 248 dairy producers were aware of foodborne pathogens in raw milk. Dairy producers who were not aware of foodborne pathogens in raw milk were 2 -fold more likely to consume raw milk compared with dairy producers who were aware of foodborne pathogens. The majority of dairy producers who consumed raw milk indicated that taste $(72 \%)$ and convenience $(60 \%)$ were the primary factors for consuming raw milk. Dairy producers who resided on the dairy farm were nearly 3 -fold more likely to consume raw milk compared with those who lived elsewhere. In the second part of the study, bulk tank milk from the 248 participating dairy herds was examined for foodborne pathogens. Campylobacter jejuni (2\%), Shiga toxin-producing Escherichia coli (2.4\%), Listeria monocytogenes (2.8\%), Salmonella (6\%), and Yersinia enterocolitica (1.2\%) were detected in the milk samples. Salmonella isolates were identified as S. enterica serotype Typhimurium ( $\mathrm{n}=10)$ and S. enterica serotype Newport $(\mathrm{n}=5)$. Of the 248 bulk tank milk samples, $32(13 \%)$ contained $\geq 1$ species of bacterial pathogens. The findings of the study could assist in developing farm community-based educational programs on the risks of consuming raw milk.
\end{abstract}

Key words: bulk tank milk, dairy, foodborne pathogens, raw milk

\section{INTRODUCTION}

Pasteurization of commercially distributed milk has greatly reduced the risk of infection resulting from the

Received September 8, 2005.

Accepted February 15, 2006

${ }^{1}$ Corresponding author: bmj3@psu.edu consumption of contaminated milk (Centers for Disease Control and Prevention, 1999; Cohen, 2000). However, a portion of the US population continues to consume raw milk and products made from it, namely, soft cheeses (Rohrbach et al., 1992; Headrick et al., 1997, 1998; Shiferaw et al., 2000; Hegarty et al., 2002). In the United States, consumption of raw bulk tank milk (BTM) is a common practice among farm families. Studies have reported that the most prevalent consumers of raw milk are dairy farm families and dairy farm employees (Shiferaw et al., 2000; Hegarty et al., 2002). A study by Rohrbach et al. (1992) reported that 34.9\% of dairy producers in eastern Tennessee and southwest Virginia consumed raw milk. Jayarao and Henning (2001) reported that $60 \%$ of dairy producers in eastern South Dakota and western Minnesota consumed raw milk. Among the nonfarming population, a growing number of consumers are claiming that raw milk is healthier and are choosing raw milk over pasteurized milk (Potter et al., 1984; Bren, 2004). In California the sale of raw milk is legal, making the state the largest producer of "certified raw milk" in the United States (Headrick et al., 1997, 1998). Certified raw milk is unpasteurized milk with a total bacterial count below a specified standard, but this is not a guarantee that the milk is free of bacterial pathogens. A survey by Headrick et al. (1997) on raw milk consumption in California showed that $3.2 \%$ of the population surveyed consumed raw milk. Elsewhere, a survey of adults from 8 US states showed that less than $2 \%$ of the participants drank raw milk (Altekruse et al., 1999b). Although raw milk advocates claim that raw milk is healthier, research has shown no significant difference in the nutritional value of pasteurized and unpasteurized milk (Potter et al., 1984; Centers for Disease Control and Prevention, 1999; Bren, 2004).

Raw milk has been a known vehicle for pathogens for more than $100 \mathrm{yr}$ (Potter et al., 1984; Centers for Disease Control and Prevention, 1999; Gillespie et al., 2003). Outbreaks associated with the consumption of raw milk occur routinely every year. In 1987 the FDA banned the interstate sale of raw milk; however, the sale of raw milk within state boundaries falls under the jurisdiction of each state's government (Bren, 2004). 
As of 1995, the intrastate sale of raw milk for human consumption was legal in 28 states (Headrick et al., 1998). In Pennsylvania, the sale of raw milk is legal on dairy farms if producers have a permit from the Department of Agriculture (Commonwealth of Pennsylvania, 2005). In many states where the off-farm sale of raw milk is prohibited, people have circumvented the law through "cow-sharing" or "cow-leasing" programs. In such programs, people pay a fee to a farmer to lease a share of a cow in exchange for raw milk (Bren, 2004; Mazurek et al., 2004). Outbreaks of foodborne illness have been linked to raw milk obtained from these cowleasing programs (Centers for Disease Control and Prevention, 2002). Consumption of certified raw milk has also been the source of outbreaks (Centers for Disease Control and Prevention, 1984a,b). Between 1973 and 1992, raw milk was associated with 46 outbreaks of foodborne illness in the United States, and it is significant to note that 40 (87\%) of these outbreaks occurred in states where the intrastate sale of raw milk was legal at the time (Headrick et al., 1998). Consumption of raw milk is a high-risk behavior and will continue to cause morbidity and mortality until people stop consuming raw milk and raw milk products (Keene, 1999).

The risk of foodborne disease has increased over the last $20 \mathrm{yr}$ (Oliver et al., 2005). Outbreaks of foodborne illnesses following consumption of raw milk and products made from raw milk caused by Shiga toxin-producing Escherichia coli (STEC; Keene et al., 1997; Wilson et al., 1998; Proctor and Davis, 2000), Salmonella spp. (Reed and Grivetti, 2000; Centers for Disease Control and Prevention, 2003; Mazurek et al., 2004), Listeria monocytogenes (Linnan et al., 1988; Centers for Disease Control and Prevention, 2001), and Campylobacter jejuni (Evans et al., 1996; Centers for Disease Control and Prevention, 2002; Peterson, 2003) have been reported in recent years. Gillespie et al. (2003) reported that between the years of 1992 and 2000, $52 \%$ of foodborne outbreaks in England and Wales were attributed to raw milk. Raw milk and products made from raw milk have been implicated in similar numbers of documented cases of foodborne illness in France (DeBuyser et al., 2001).

Gastroenteritis is the primary condition associated with cases of foodborne illness attributable to raw milk consumption. Although enteritis caused by foodborne pathogens such as STEC and Salmonella spp. is usually self-limiting, immunocompromised individuals are at a higher risk of serious illness. Foodborne C. jejuni and Yersinia enterocolitica illnesses are typically characterized by gastritis and enterocolitis; however, debilitating postinfection immunologic sequelae, including Guillian-Barré syndrome (Altekruse et al., 1999a; Oliver et al., 2005) and reactive arthritis (Schiemann, 1987), are known to develop in some individuals following an episode of foodborne illness with these pathogens. Unlike other foodborne bacteria, which cause mainly gastritis and enteritis, L. monocytogenes causes listeriosis, which is characterized by septicemia and meningitis in humans (Oliver et al., 2005).

Limited epidemiological data exist on raw milk consumption and the corresponding risk of foodborne illness. Furthermore, the long-term effects on human health of continued exposure to milkborne pathogens are unknown. The purpose of this study was to ascertain information on: 1) raw milk consumption practices of dairy producers, and 2) the prevalence of foodborne pathogens in BTM in Pennsylvania.

\section{MATERIALS AND METHODS}

\section{Participants}

Dairy producers $(n=914)$ from 51 counties in Pennsylvania were mailed a letter soliciting their participation in the study. A total of 374 dairy producers (271 and 103 respondents on the first and second mailings, respectively) consented to participate in the study. Of the 374 dairy producers who consented to the study, 265 participated in the first part of the study (a selfadministered questionnaire survey), and 248 participated in both the first and second parts of the study (the analysis of BTM for foodborne pathogens).

\section{Questionnaire Survey}

The self-administered questionnaire survey used by Jayarao and Cassel (1999) was modified to collect information on demographics (income, education, residence, raw milk use by employees, source of milk, knowledge of foodborne pathogens) and on attributes that influence raw milk consumption practices (taste, health, convenience, cost, and other reasons). The responses to each of the questions were entered into a Microsoft Excel spreadsheet. For each question, a test of significance ( $\chi^{2}$ test) was applied to determine the difference in responses to the questions between dairy producers who consumed raw milk and those who did not. Epiinfo-2002 (Centers for Disease Control and Prevention, Atlanta, GA), a database and statistical system for epidemiology on microcomputers, was used for performing $\chi^{2}$ tests and odds ratio analyses. Statistical significance was accepted at $P<0.05$.

\section{Collection of BTM}

Bulk tank milk from the dairy herds $(\mathrm{n}=248)$ was examined for C. jejuni, STEC, L. monocytogenes, Salmonella spp., and Y. enterocolitica. A single BTM sample 
(approximately $120 \mathrm{~mL}$ ) was collected in a sterile snapcap milk collection vial from each of the 248 dairy producers between July 1, 2001, and June 30, 2002. Milk samples were collected by county extension agents, dairy producers, or laboratory personnel following the National Mastitis Council (1999) standards for BTM sample collection and handling. The county extension agent provided on-farm instruction to the dairy producer on BTM collection and handling procedures as described by the National Mastitis Council. Briefly, milk in the bulk tank was agitated before collection, and samples were taken from the top of the bulk tank using a sanitized dipper. Within $36 \mathrm{~h}$ of collection, all milk samples from the region were shipped on ice overnight to the laboratory. On receipt of the sample in the laboratory, only those samples that recorded a temperature of $<7^{\circ} \mathrm{C}$ were processed.

\section{Isolation of Foodborne Pathogens from BTM}

Isolation of $C$. jejuni from raw milk was performed as described by Hunt et al. (2001). Enriched broth and plates were incubated in a microaerophilic atmosphere that was created by using a gas-generating kit for Campylobacter in an anaerobic jar (Oxoid Ltd., Basingstoke, UK). All presumptive Campylobacter isolates were identified to genus level as described by Hunt et al. (2001) and then speciated using the API-CAMPY identification kit (BioMérieux, Hazelwood, MO).

Escherichia coli was isolated from raw milk as described by Jayarao and Henning (2001) with the following modifications. Briefly, $10 \mathrm{~mL}$ of raw milk was added to $90 \mathrm{~mL}$ of trypticase soy broth (Difco Laboratories, Detroit, MI) supplemented with $20 \mu \mathrm{g} / \mathrm{mL}$ of novobiocin (Sigma Chemical Co., St. Louis, MO) and incubated overnight at $37^{\circ} \mathrm{C}$. Escherichia coli were isolated by subculturing $50 \mu \mathrm{L}$ of enriched sample onto MacConkey agar supplemented with 4-methylumbelliferyl-beta glucuronide (Difco Laboratories). The plates were incubated for $48 \mathrm{~h}$ at $42^{\circ} \mathrm{C}$. At least 5 to 10 fluorescent colonies from MacConkey-methylumbelliferyl-beta glucuronide plates were selected for further characterization. For detection of $E$. coli $\mathrm{O} 157: \mathrm{H} 7,50 \mu \mathrm{L}$ of enriched sample was spread on sorbitol MacConkey agar (Difco Laboratories) supplemented with cefixime $(0.05$ $\mathrm{mg} / \mathrm{L})$ and potassium tellurite $(2.5 \mathrm{mg} / \mathrm{L}$; Dynal Inc., Lake Success, NY) and incubated for $48 \mathrm{~h}$ at $42^{\circ} \mathrm{C}$. At least 510 sorbitol-negative colonies from sorbitol MacConkey agar were tested with $\mathrm{O} 157$ antigen by latex agglutination (Unipath Co., Ogdensburg, NY). Isolates identified as belonging to the genus Escherichia were screened for the presence of Shiga toxin $1\left(s t x_{1}\right)$ and Shiga toxin $2\left(s t x_{2}\right)$ genes as described by Meng et al.
(1997). Isolates that carried the Shiga toxin genes were speciated using API 20E (BioMérieux).

Listeria monocytogenes was isolated from raw milk as described by Jayarao and Henning (2001). All isolates were examined for Gram's reaction, hemolysis, and the Christie, Atkins, Munch-Petersen reaction on $5 \%$ sheep blood agar, catalase production, nitrate reduction, and motility on sulfide-indole production-motility medium (Becton, Dickinson \& Co., Cockeysville, MD). All isolates were confirmed to species by use of the APIListeria identification kit (BioMérieux). Isolates identified as L. monocytogenes were serotyped using $\mathrm{O}$ antisera (Difco Laboratories).

Isolation of Salmonella from raw milk was performed as described by Jayarao and Henning (2001) with modifications. Briefly, $25 \mathrm{~mL}$ of milk was added to $225 \mathrm{~mL}$ of lactose broth and incubated for $24 \mathrm{~h}$ at $37^{\circ} \mathrm{C}$. Approximately 0.1 and $1 \mathrm{~mL}$ of preenriched samples were transferred to Rappaport-Vassiliadis medium and tetrathionate broth, respectively (Difco Laboratories), followed by $24 \mathrm{~h}$ of incubation at 42 and $37^{\circ} \mathrm{C}$, respectively. The enrichments were streaked on Hektoen enteric agar (Difco Laboratories) and xylose lysine desoxycholate agar (Unipath Co.) and incubated for $24 \mathrm{~h}$ at $35^{\circ} \mathrm{C}$. All presumptive Salmonella colonies were inoculated on triple sugar iron agar and urease agar (Difco Laboratories) incubated at $37^{\circ} \mathrm{C}$ for $24 \mathrm{~h}$, and were tested with Salmonella polyvalent O antiserum (Difco Laboratories). Organisms that gave typical reactions for Salmonella were then speciated using an API-20E identification kit (BioMérieux). Isolates were then tested by seroagglutination using Salmonella O group (A-I) antisera (Difco Laboratories).

Yersinia enterocolitica was isolated from raw milk as described by Weagant et al. (2001). Briefly, $10 \mathrm{~mL}$ of milk was added to $90 \mathrm{~mL}$ of peptone sorbitol bile broth and incubated at $10^{\circ} \mathrm{C}$ for $10 \mathrm{~d}$. On d 10 , the enriched broth was treated with $0.5 \% \mathrm{KOH}$ and plated on MacConkey's agar and cefsulodin-irgasan-novobiocin agar (Difco Laboratories). After $48 \mathrm{~h}$ of incubation at room temperature, all presumptive Yersinia colonies were examined on lysine arginine iron agar, Christensen's urea agar, and bile esculin agar (Difco Laboratories). Organisms identified as Yersinia were speciated using the API-20E identification kit (BioMérieux). Isolates of $Y$. enterocolitica were presumed to be pathogenic based on a positive reaction to the autoagglutination test described by Laird and Cavanaugh (1980).

Epi-info-2002 (Centers for Disease Control and Prevention, Atlanta, GA), a database and statistical system for epidemiology on microcomputers, was used to perform $\chi^{2}$ tests and odds ratio analyses on the occurrence of pathogenic bacteria in raw milk in relation to milk 
Table 1. Demographic indicators of dairy producers who participated in the study

\begin{tabular}{|c|c|c|c|}
\hline \multirow[b]{2}{*}{ Indicators } & \multicolumn{2}{|c|}{ Consume raw milk (\%) } & \multirow[b]{2}{*}{ Total $(\%)$} \\
\hline & Yes $(n=105)$ & No $(\mathrm{n}=143)$ & \\
\hline \multicolumn{4}{|l|}{ Income } \\
\hline$<\$ 10,000$ & $21(20)$ & $14(9.8)$ & $35(14.1)$ \\
\hline$\$ 10,000-19,999$ & $29(27.6)$ & $31(21.6)$ & $60(24.2)$ \\
\hline$\$ 20,000-34,000$ & $40(38)$ & $52(36.3)$ & $92(37.1)$ \\
\hline$\$ 35,000-75,000$ & $16(15)$ & $33(23)$ & $49(19.8)$ \\
\hline$>\$ 75,000$ & $9(8.6)$ & $13(9)$ & $22(8.8)$ \\
\hline \multicolumn{4}{|l|}{ Education } \\
\hline High school & $73(69.5)$ & $80(56)$ & $153(62)$ \\
\hline Trade school & $7(6.7)$ & $21(14.6)$ & $28(11.3)$ \\
\hline College & $14(13.4)$ & $23(16)$ & $37(15)$ \\
\hline Other & $11(10.4)$ & $19(13.2)$ & $40(16.1)$ \\
\hline \multicolumn{4}{|l|}{ Residence $^{1}$} \\
\hline On dairy farm & $71(68)$ & $62(43)$ & $133(54)$ \\
\hline Away from farm & $34(32)$ & $81(57)$ & $115(46)$ \\
\hline \multicolumn{4}{|c|}{ Employees consume raw milk } \\
\hline Yes & $19(18)$ & $41(28.6)$ & $60(24.2)$ \\
\hline No & $86(82)$ & $102(71.4)$ & $188(76)$ \\
\hline \multicolumn{4}{|l|}{ Milk source $^{2}$} \\
\hline Own farm & $105(100)$ & $72(50.4)$ & $177(71.4)$ \\
\hline Grocery store & $7(6.7)$ & $71(49.6)$ & $78(31.4)$ \\
\hline \multicolumn{4}{|c|}{ Aware of foodborne pathogens ${ }^{3}$} \\
\hline Yes & $61(58)$ & $109(76.2)$ & $170(68.5)$ \\
\hline No & $44(42)$ & $34(23.7)$ & $78(31.4)$ \\
\hline
\end{tabular}

${ }^{1}$ Residence: test of significance, $\chi^{2}(P)=13.37(0.0002)$; odds ratio (confidence interval) $=2.73(1.46-$ 4.78).

${ }^{2}$ Milk source: test of significance, $\chi^{2}(P)=53.69(0.0000)$; odds ratio (confidence interval) $=14.79(6.12-$ 37.41).

${ }^{3}$ Aware of pathogens: test of significance, $\chi^{2}(P)=8.41(0.0037)$; odds ratio $($ confidence interval $)=2.31$ $(1.29-4.15)$.

consumption practices. Statistical significance was accepted at $P<0.05$.

\section{RESULTS}

A total of 248 (28\%) of the 914 dairy producers from 16 counties in Pennsylvania participated in the study. Of the 248 dairy producers surveyed, 105 (42.3\%) dairy producers reported that they consumed raw milk. There were no significant differences in the income and educational level between dairy producers who consumed raw milk and those who did not. Dairy producers who resided on the dairy farm premises were nearly 3 -fold more likely to consume raw milk than those who did not reside on the dairy farm $\left(\chi^{2}=13.37, P<0.0005\right.$; Table 1). All of the 105 dairy producers who consumed raw milk obtained the raw milk from their own farms. Over half (68.5\%) of the 248 dairy producers surveyed were aware of the fact that raw milk could contain disease-causing bacteria. Dairy producers who were not aware of foodborne pathogens in raw milk were 2 -fold more likely to consume raw milk than producers who were aware of foodborne pathogens $\left(\chi^{2}=8.41, P<\right.$ 0.005 ). About $24 \%$ of the dairy producers indicated that their employees were allowed to take raw milk that was produced on the farm (Table 1). The relevance of raw milk attributes (taste, health and nutritional value, convenience, and cost) and their influence on raw milk consumption were evaluated (Table 2). Dairy producers who consumed raw milk indicated that convenience (60\%, availability of raw milk) and taste $(72 \%)$ were the most important attributes.

Farm BTM samples from 248 dairy herds in 16 counties in Pennsylvania were examined for foodborne pathogens. Pathogenic organisms were isolated from $26(10.5 \%)$ of 248 BTM samples. Campylobacter jejuni, STEC, L. monocytogenes, Salmonella spp., and Y. enterocolitica were detected in 2.0,2.4, 2.8, 6.0, and $1.2 \%$ of BTM samples, respectively (Table 3). Overall, 32 (13\%) of the 248 BTM samples had $\geq 1$ bacterial pathogen. Salmonella isolates were identified as $S$. enterica serotype Typhimurium $(\mathrm{n}=10)$ and $S$. enterica serotype Newport $(\mathrm{n}=5)$. All L. monocytogenes $(\mathrm{n}=3)$ were identified as $\mathrm{O}$ antigen type 1 . The $s t x_{2}$ gene was present in 5 of the 6 STEC isolates, and 1 strain encoded for the $s t x_{1}$ gene. Escherichia coli $\mathrm{O} 157: \mathrm{H} 7$ was not isolated from the BTM samples. Based on an autoagglutination test, we concluded that all $Y$. enterocolitica $(n=3)$ were pathogenic. 
Table 2. Reasons cited by farm families for consuming milk

\begin{tabular}{|c|c|c|c|c|c|}
\hline \multirow[b]{2}{*}{ Attributes } & \multicolumn{5}{|c|}{ Response to raw milk consumption $(\mathrm{n}=105)$} \\
\hline & Taste & Health & Convenience & Cost & Other $^{1}$ \\
\hline Taste alone & 13 & & & & \\
\hline Health alone & & 3 & & & \\
\hline Convenience alone & & & 13 & & \\
\hline Cost alone & & & & 1 & \\
\hline Other ${ }^{1}$ alone & & & & & 5 \\
\hline Taste + health & 11 & 11 & & & \\
\hline Taste + health + convenience & 9 & 9 & 9 & & \\
\hline Taste + health + convenience + cost & 25 & 25 & 25 & 25 & \\
\hline Taste + cost & 4 & & & 4 & \\
\hline Taste + convenience & 12 & & 12 & & \\
\hline Convenience + cost & & & 3 & 3 & \\
\hline Other $^{1}+$ taste, health, convenience, or cost & 2 & 1 & 1 & 4 & 6 \\
\hline Total & 76 & 49 & 63 & 37 & 11 \\
\hline$\%$ & 72 & 47 & 60 & 35 & 10 \\
\hline
\end{tabular}

${ }^{1}$ Safe (2), no chemicals (3), clean (2), refreshing and homemade (4).

In this study, 105 (42.3\%) of the 248 dairy producers who participated in the BTM pathogen survey reported that they consumed raw milk. Bacteriologic analysis of BTM showed that 15 (14.2\%) of the 105 producers who consumed raw milk had $\geq 1$ bacterial pathogen isolated from their bulk tank (Table 3). There was no significant difference in the incidence of pathogenic bacteria in the raw milk of dairy producers who did and did not consume raw milk $(P>0.05)$.

\section{DISCUSSION}

In the United States, foodborne illnesses are estimated to cause 76 million illnesses and 5,000 deaths each year (Mead et al., 1999). The FDA banned the interstate sale of raw milk in 1987; however, the intrastate sale of raw milk for human consumption was legal in 28 states as of 1995 (Headrick et al., 1998). Despite the known association of raw milk with pathogenic organisms, some consumers believe raw milk is of better quality than pasteurized milk (Potter et al. 1984; Bren, 2004). In the United States, more than 500 people became ill in 2001 and 2002 from drinking raw milk or from consuming soft cheeses made from raw milk (Bren, 2004).

Consumption of raw milk is practiced by dairy producers for several reasons. Many farm families consume raw milk simply because it is a traditional practice and less expensive to take milk from the bulk tank than to buy retail pasteurized milk. In this study, $42.3 \%$ of dairy producers surveyed reported drinking raw BTM, and reported taste and convenience as the primary reasons for choosing to consume raw milk over retail pasteurized milk. A survey of Irish dairy producers reported that many farmers believed raw milk had higher nutritional value than pasteurized milk (Heg-

Table 3. Prevalence of pathogens in bulk tank milk

\begin{tabular}{|c|c|c|c|c|c|}
\hline \multirow[b]{2}{*}{ Organism } & \multirow{2}{*}{$\begin{array}{l}\text { No. }(\%) \text { of isolates } \\
\text { from bulk tank } \\
\text { milk }(\mathrm{n}=248)\end{array}$} & \multicolumn{2}{|c|}{ Combination of pathogens } & \multicolumn{2}{|c|}{$\begin{array}{c}\text { Consume raw } \\
\text { milk }^{1}(\mathrm{n}=248)\end{array}$} \\
\hline & & Organism(s) & $\begin{array}{l}\text { Bulk tanks } \\
(\mathrm{n}=248)\end{array}$ & $\begin{array}{l}\text { Yes } \\
(\mathrm{n}=105)\end{array}$ & $\begin{array}{l}\text { No } \\
(\mathrm{n}=143)\end{array}$ \\
\hline \multirow[t]{4}{*}{ Salmonella spp. } & \multirow[t]{4}{*}{$15(6.0)$} & Salmonella & 11 & 7 & 4 \\
\hline & & + E. coli & 2 & 1 & 1 \\
\hline & & + L. monocytogenes & 1 & 1 & - \\
\hline & & $+Y$. enterocolitica & 1 & 1 & - \\
\hline Listeria monocytogenes & $3(1.2)$ & L. monocytogenes & 2 & 1 & 1 \\
\hline \multirow[t]{2}{*}{ Campylobacter jejuni } & \multirow[t]{2}{*}{$5(2.2)$} & C. jejuni & 3 & 2 & 1 \\
\hline & & + E. coli & 2 & 1 & 1 \\
\hline Yersinia enterocolitica & $3(1.2)$ & Y. enterocolitica & 2 & - & 2 \\
\hline STEC $^{2}$ & $6(2.4)$ & E. coli & 2 & 1 & 1 \\
\hline Total & $32(13 \%)$ & & 26 & 15 & 11 \\
\hline
\end{tabular}


arty et al., 2002). Multistate surveys on food consumption behaviors have reported that raw milk consumption is most common among men, younger people (ages 18 to $29 \mathrm{yr}$ ), people of Hispanic descent, people earning less than $\$ 15,000 / y r$, and those who live on a farm or in a rural area (Yang et al., 1998; Shiferaw et al., 2000). In our study, dairy producers who resided on the dairy farm premises were nearly 3 -fold more likely to consume raw milk than those who resided away from the farm. Previous studies have reported that people with less than a high school education are more likely to consume raw milk than those who have completed high school, suggesting that the level of education may influence raw milk consumption habits (Headrick et al., 1997; Yang et al., 1998; Altekruse et al., 1999b; Shiferaw et al., 2000). However, we found no significant difference based on education level or income in this study.

Dairy farms are considered reservoirs of many foodborne pathogens, including Salmonella, Listeria, Campylobacter, and STEC (Oliver et al., 2005). The presence of these and other pathogens in BTM is the result of fecal contamination on teats, udder surfaces, and milking machines (Jayarao and Wang, 1999). In this study, C. jejuni, STEC, L. monocytogenes, Salmonella spp., and $Y$. enterocolitica were detected in 2.0, $2.4,2.8,6.0$, and $1.2 \%$ of BTM samples, respectively. Similar isolation rates have been reported in studies of BTM (Rohrbach et al., 1992; Jayarao and Henning, 2001). Van Kessel et al. (2004) reported results on the prevalence of foodborne pathogens in BTM as part of the USDA's National Animal Health Monitoring System Dairy 2002 Survey. They observed a higher isolation rate for L. monocytogenes $(6.5 \%)$ and a lower rate for Salmonella spp. (2.6\%) in BTM compared with our study (Van Kessel et al., 2004).

Each year, an estimated 2.1 to 2.4 million cases of human campylobacteriosis occur, making it the most commonly reported bacterial cause of foodborne infection in the United States (Altekruse et al., 1999a; Mead et al., 1999). Campylobacter jejuni is found in many foods of animal origin and has frequently been isolated from raw BTM (Rohrbach et al., 1992; Jayarao and Henning, 2001; Peterson, 2003). In this study C. jejuni was found in $2 \%$ of the BTM samples. Previous studies have reported the prevalence of $C$. jejuni in raw milk samples as ranging from $<1$ to $12 \%$ (Rohrbach et al., 1992; Jayarao and Henning, 2001). Outbreaks of $C$. jejuni enteritis caused by drinking raw milk are often associated with youth activities such as school trips to farms (Wood et al., 1992; Altekruse et al., 1999a).

Dairy cattle can serve as reservoirs of STEC strains that can cause illnesses in humans through contaminated milk, from meat supplied through cull animals, and by direct contact with cattle or the dairy farm environment. Shiga toxin-producing E. coli are highly pathogenic in humans with low infectious doses (Nataro and Kaper, 1998; Hussein and Sakuma, 2005). Among the STEC, O157:H7 is the classical serotype associated with enterohemorrhagic diseases. Non-O157 STEC strains are only recently becoming recognized as important human pathogens (Nataro and Kaper, 1998; Hussein and Sakuma, 2005). Consumption of raw milk has been implicated as the cause in several outbreaks of disease caused by E. coli O157:H7 (Keene et al., 1997; Proctor and Davis, 2000) and by non-O157 STEC (Wilson et al., 1998; Hussein and Sakuma, 2005). Shiga toxin-producing $E$. coli excrete potent Shiga toxins that are encoded by the $s t x_{1}$ and $s t x_{2}$ genes, respectively (Hussein and Sakuma, 2005). The STEC isolates in this study predominantly carried the $s t x_{2}$ gene. Epidemiological data suggest that st $x_{2}$ is more important than $s t x_{1}$ in the development of hemolytic uremic syndrome, a life-threatening illness associated with STEC infection in children (Nataro and Kaper, 1998).

Contamination with $L$. monocytogenes was the leading cause of food recalls by the FDA from 1994 to 1998 (Wong et al., 2000). In this study, all L. monocytogenes belonged to $\mathrm{O}$ antigen type 1 . The $\mathrm{O}$ antigen includes serotypes $1 / 2 \mathrm{a}, 1 / 2 \mathrm{~b}$, and $1 / 2 \mathrm{c}$; and serotypes $1,1 / 2 \mathrm{a}, 1 /$ $2 \mathrm{~b}$, and $4 \mathrm{~b}$ have been found in raw milk (Jayarao and Henning, 2001; Van Kessel et al., 2004). Outbreaks of L. monocytogenes have been associated with homemade Latin-style soft cheeses made from unpasteurized raw milk. These outbreaks occur primarily in Hispanic communities, with many of the cases involving pregnant women (Linnan et al., 1988; Centers for Disease Control and Prevention, 2001). Listeriosis is a major public health concern in these communities because pregnant women are especially susceptible to $L$. monocytogenes, which can cross the placenta and cause spontaneous abortions and stillbirths (Oliver et al., 2005).

Generally, dairy cattle are not considered reservoirs of pathogenic Y. enterocolitica (Jayarao and Henning, 2001). In humans, $Y$. enterocolitica is an important foodborne pathogen and is mainly transmitted through consumption of contaminated pork, milk, or water. Raw milk frequently contains $Y$. enterocolitica, but outbreaks of foodborne infection are not commonly reported (Schiemann, 1987; Jayarao and Henning, 2001). In this study, all Yersinia isolates were pathogenic based on the autoagglutination test described by Laird and Cavanaugh (1980).

An estimated 1.4 million cases of salmonellosis occur annually in the United States (Mead et al., 1999). Sales of raw milk directly to the public have resulted in foodborne outbreaks of multidrug-resistant salmonellosis in California and Washington (Reed and Grivetti, 2000), 
Ohio, Illinois, Indiana, and Tennessee (Centers for Disease Control and Prevention, 2003). In this study, Salmonella was the predominant organism isolated from BTM. The Salmonella isolates were identified as $S$. enterica serotype Typhimurium $(\mathrm{n}=10)$ and S. enterica serotype Newport ( $\mathrm{n}=5$ ). The emergence of multidrugresistant $S$. enterica serotype Typhimurium definitive type 104 and multidrug-resistant $S$. enterica serotype Newport is of particular concern to public health agencies (Keene, 1999; Jayarao and Henning, 2001; Oliver et al., 2005).

The isolation of foodborne pathogenic bacteria in raw milk has been reported extensively in Canada and United States (Rohrbach et al., 1992; Jayarao and Henning, 2001; Oliver et al., 2005). The isolation rate reported over the last 2 decades varies considerably. We feel that this variation could be attributed partly to the techniques used for isolation and identification of the pathogens, their true prevalence, sample size, season, geographic area, farm size, the number of animals on the farm, hygiene, and farm management practices. In this study, only a single BTM sample was examined for each farm. It seems likely to assume that repeated sampling would result in a higher overall incidence of pathogen detection at the farm level. Our findings clearly suggest that pathogens do occur in BTM and may pose a health hazard if milk is consumed raw. In this study, $105(42.3 \%)$ of the 248 dairy producers who participated in the BTM pathogen survey reported that they consumed raw milk. Bacteriologic analysis of BTM showed that $15(14.2 \%)$ of the 105 producers who consumed raw milk had $\geq 1$ bacterial pathogen isolated from their bulk tank. Other studies have reported that 26.6 (Jayarao and Henning, 2001) and 25\% (Rohrbach et al., 1992) of producers who consumed raw milk had $\geq 1$ bacterial pathogen in their BTM. There was no significant difference in the incidence of pathogenic bacteria in raw milk of the dairy producers who did and did not consume raw milk $(P>0.05)$. Similar results were seen by Jayarao and Henning (2001).

Two-thirds $(68.5 \%)$ of the 248 dairy producers surveyed were aware of the fact that raw milk could contain disease-causing bacteria, meaning roughly one-third of the dairy producers surveyed were not aware of the risk of foodborne pathogens in their BTM. However, out of the 105 dairy producers who drank raw milk, 61 (58.1\%) reported that they continued to drink raw milk despite knowing that foodborne pathogens could be found in their raw BTM. The continuation of this highrisk behavior in spite of their awareness is a concern.

\section{CONCLUSIONS}

The findings of this study suggest that pathogenic bacteria of human health significance can be found in raw milk. This observation, along with previously reported data on consumption of raw milk, indicates that dairy producers and farm families are at risk for exposure to foodborne pathogens when consuming raw milk. Consumption of raw milk is a preventable cause of foodborne illness, making pasteurization of raw milk an important public health tool for foodborne disease prevention. Yet one of the most surprising findings of this study was the fact that $31.4 \%$ of the dairy producers surveyed were unaware that their raw BTM could contain disease-causing microorganisms. These findings suggest a lack of knowledge among dairy producers about the risks associated with raw milk consumption. One way to approach this problem would be to develop educational outreach programs for dairy producers, as well as for the general public, that focus on issues related to the consumption of raw milk. This study shows that C. jejuni, STEC, L. monocytogenes, Salmonella spp., and Y. enterocolitica can be found in BTM. The prevalence rates were similar to other reports from the United States of foodborne pathogens in BTM. This study suggests a risk of exposure to foodborne pathogens among the dairy farm families who consume unpasteurized BTM.

\section{ACKNOWLEDGMENTS}

The authors would like to acknowledge the participation and support of Extension Agents of the Penn State Cooperative Extension. The participating milk cooperatives are also recognized for their assistance in this study. Dairy producers and their veterinarians who participated in the study are also acknowledged. This study was funded in part by the USDA-Milk Safety Special Grant 2001.

\section{REFERENCES}

Altekruse, S. F., N. J. Stern, P. I. Fields, and D. L. Swerdlow. 1999a. Campylobacter jejuni-An emerging foodborne pathogen. Emerg. Infect. Dis. 5:28-35.

Altekruse, S. F., S. Yang, B. B. Timbo, and F. J. Angulo. 1999b. A multi-state survey of consumer food-handling and food-consumption practices. Am. J. Prev. Med. 16:216-221.

Bren, L. 2004. Got milk? Make sure it's pasteurized. FDA Consum. 38:29-31.

Centers for Disease Control and Prevention. 1984a. Epidemiologic notes and reports Campylobacter outbreak associated with certified raw milk products-California. Morb. Mortal. Wkly. Rep. 33:562.

Centers for Disease Control and Prevention. 1984b. Salmonella dublin and raw milk consumption-California. Morb. Mortal. Wkly. Rep. 33:196-198.

Centers for Disease Control and Prevention. 1999. Achievements in public health, 1900-1999: Safer and healthier foods. Morb. Mortal. Wkly. Rep. 48:905-913.

Centers for Disease Control and Prevention. 2001. Outbreak of listeriosis associated with homemade Mexican-style cheese-North Carolina, October 2000-January 2001. Morb. Mortal. Wkly. Rep. 50:560-562. 
Centers for Disease Control and Prevention. 2002. Outbreak of Campylobacter jejuni infections associated with drinking unpasteurized milk procured through a cow-leasing program-Wisconsin, 2001. Morb. Mortal. Wkly. Rep. 51:548-549.

Centers for Disease Control and Prevention. 2003. Multistate outbreak of Salmonella serotype Typhimurium infections associated with drinking unpasteurized milk-Illinois, Indiana, Ohio, and Tennessee, 2002-2003. Morb. Mortal. Wkly. Rep. 52:613-615.

Cohen, M. L. 2000. Changing patterns of infectious disease. Nature 406:762-767.

Commonwealth of Pennsylvania. 2005. Laws of the General Assembly of the Commonwealth of Pennsylvania. 31 P.S. §§ 646, 652.

DeBuyser, M. L., B. Dufour, M. Maire, and V. Lafarge. 2001. Implication of milk and milk products in food-borne diseases in France and in different industrialized countries. Int. J. Food Microbiol. 67:1-17.

Evans, M. R., R. J. Roberts, C. D. Ribeiro, D. Gardner, and D. Kembrey. 1996. A milk-borne Campylobacter outbreak following an educational farm visit. Epidemiol. Infect. 117:457-462.

Gillespie, I. A., G. K. Adak, S. J. O’Brien, and F. J. Bolton. 2003. Milkborne general outbreaks of infectious intestinal disease, England and Wales, 1992-2000. Epidemiol. Infect. 130:461-468.

Headrick, M. L., S. Korangy, N. H. Bean, F. J. Angulo, S. F. Altekruse, M. E. Potter, and K. C. Klontz. 1998. The epidemiology of raw milk-associated foodborne disease outbreaks reported in the United States, 1973 through 1992. Am. J. Pubic Health. 88:1219-1221.

Headrick, M. L., B. Timbo, K. C. Klontz, and S. B. Werner. 1997. Profile of raw milk consumers in California. Public Health Rep. 112:418-422.

Hegarty, H., M. B. O’Sullivan, J. Buckley, and C. Foley-Nolan. 2002. Continued raw milk consumption on farms: Why? Commun. Dis. Public Health 5:151-156.

Hunt, J. M., C. Abeyta, and T. Tran. 2001. Campylobacter. In FDA Bacteriological Analytical Manual Online. 8th ed., rev. A. http:// www.cfsan.fda.gov/ ebam/bam-7.html Accessed June 5, 2005.

Hussein, H. S., and T. Sakuma. 2005. Prevalence of Shiga-toxin producing Escherichia coli in dairy cattle and their products. J. Dairy Sci. 88:450-465.

Jayarao, B. M., and E. K. Cassel. 1999. Mastitis prevention and milk hygiene practices adopted by dairy producers. Large Anim. Pract. 20:6-14.

Jayarao, B. M., and D. R. Henning. 2001. Prevalence of foodborne pathogens in raw milk. J. Dairy Sci. 84:2157-2162.

Jayarao, B. M., and L. Wang. 1999. A study on the prevalence of gramnegative bacteria in bulk tank milk. J. Dairy Sci. 82:2620-2624.

Keene, W. E. 1999. Lessons from investigations of foodborne disease outbreaks. J. Am. Med. Assoc. 281:1845-1847.

Keene, W. E., K. Hedberg, D. E. Herriott, D. D. Hancock, R. W. McKay, T. J. Barett, and D. W. Fleming. 1997. A prolonged outbreak of Escherichia coli O157:H7 infections caused by commercially distributed raw milk. J. Infect. Dis. 176:815-818.

Laird, W. J., and D. C. Cavanaugh. 1980. Correlation of autoagglutination and virulence of Yersinia. J. Clin. Microbiol. 27:1667-1670.

Linnan, M. J., L. Mascola, X. D. Lou, V. Goulet, S. May, C. Salminen, D. W. Hird, M. L. Yonekura, P. Hayes, R. Weaver, A. Audrier, B. D. Plikaytis, S. L. Fannin, A. Kleks, and C. V. Broome. 1988 Epidemic listeriosis associated with Mexican-style cheese. N. Engl. J. Med. 319:823-828.

Mazurek, J., E. Salehi, D. Propes, J. Holt, T. Bannerman, L. M. Nicholson, M. Bundesen, R. Duffy, and R. L. Moolenaar. 2004. A multistate outbreak of Salmonella enterica serotype Typhimurium infection linked to raw milk consumption-Ohio, 2003. J. Food Prot. 67:2165-2170.
Mead, P. S., L. Slutsker, V. Dietz, L. F. McCaig, J. S. Bresee, C. Shapiro, P. M. Griffin, and R. V. Tauxe. 1999. Food-related illness and death in the United States. Emerg. Infect. Dis. 5:607-625.

Meng, J., S. Zhao, M. P. Doyle, S. E. Mitchell, and S. Kresovich. 1997. A multiplex PCR for identifying Shiga-like toxin-producing Escherichia coli O157:H7. Lett. Appl. Microbiol. 24:172-176.

Nataro, J. P., and J. B. Kaper. 1998. Diarrheagenic Escherichia coli. Clin. Microbiol. Rev. 11:142-201.

National Mastitis Council. 1999. Bulk tank cultures. Pages 171173 in Laboratory Handbook on Bovine Mastitis. Rev. ed. Natl. Mastitis Council, Madison, WI.

Oliver, S. P., B. M. Jayarao, and R. A. Almeida. 2005. Foodborne pathogens in milk and the dairy farm environment: Food safety and public health implications. Foodborne Pathog. Dis. 2:115129.

Peterson, M. C. 2003. Campylobacter jejuni enteritis associated with consumption of raw milk. J. Environ. Health 65:20-21.

Potter, M. E., A. F. Kaufmann, P. A. Blake, and R. A. Feldman. 1984. Unpasteurized milk: The hazards of a health fetish. J. Am. Med. Assoc. 252:2048-2052.

Proctor, M. E., and J. P. Davis. 2000. Escherichia coli O157:H7 infections in Wisconsin 1992-1999. Wis. Med. J. 99:32-37.

Reed, B. A., and L. E. Grivetti. 2000. Controlling on-farm inventories of bulk-tank raw milk-An opportunity to protect public health. J. Dairy Sci. 83:2988-2991.

Rohrbach, R. W., F. A. Draughon, P. M. Davidson, and S. P. Oliver. 1992. Prevalence of Listeria monocytogenes, Campylobacter jejuni, Yersinia enterocolitica and Salmonella in bulk tank milk: Risk factors and risk of human exposure. J. Food Prot. 55:93-97.

Schiemann, D. A. 1987. Yersinia enterocolitica in milk and dairy products. J. Dairy Sci. 70:383-391.

Shiferaw, B., S. Yang, P. Cieslak, D. Vugia, R. Marcus, J. Koehler, V. Deneen, and F. Angulo, and The Foodnet Working Group. 2000. Prevalence of high-risk food consumption and food-handling practices among adults: A multistate survey, 1996 to 1997. J. Food Prot. 63:1538-1543.

Van Kessel, J. S., J. S. Karns, L. Gorski, B. J. McCluskey, and M. L. Perdue. 2004. Prevalence of Salmonellae, Listeria monocytogenes, and fecal coliforms in bulk tank milk on US dairies. J. Dairy Sci. 87:2822-2830.

Weagant, S. D., P. Feng, and J. T. Stanfield. 2001. Yersinia enterocolitica and Yersinia pseudotuberculosis. FDA Bacteriological Analytical Manual Online. 8th ed., rev. A. http://www.cfsan.fda.gov/ ebam/bam-8.html\#authors Accessed June 5, 2005.

Wilson, J. B., R. C. Clarke, S. A. Renwick, K. Rahn, R. P. Johnson, M. A. Karmali, H. Lior, D. Alves, C. L. Gyles, K. S. Sandhu, S. A. McEwen, and J. S. Spika. 1998. Vero cytotoxigenic Escherichia coli infection in dairy farm families. J. Infect. Dis. 177:1139-1140.

Wong, S., D. Street, S. I. Delgado, and K. C. Klontz. 2000. Recalls of foods and cosmetics due to microbial contamination reported to the U.S. Food and Drug Administration. J. Food Prot. 63:1113-1116.

Wood, R. C., K. L. MacDonald, and M. T. Osterholm. 1992. Campylobacter enteritis outbreaks associated with drinking raw milk during youth activities. A 10-year review of outbreaks in the United States. J. Am. Med. Assoc. 268:3228-3230.

Yang, S., M. G. Leff, D. McTague, K. A. Horvath, J. Jackson-Thompson, T. Murayi, G. K. Boeselager, T. A. Melnik, M. C. Gildemaster, D. L. Ridings, S. F. Altekruse, and F. J. Angulo. 1998. Multistate surveillance for food-handling, preparation, and consumption behaviors associated with foodborne diseases: 1995 and 1996 BRFFSS food-safety questions. Morb. Mortal. Wkly. Rep. 47:SS4:33-SS-4:54 